5.

ABRIL $\cdot 2019$
Ponte de Lima:

do passado ao presente, rumo ao futuro!

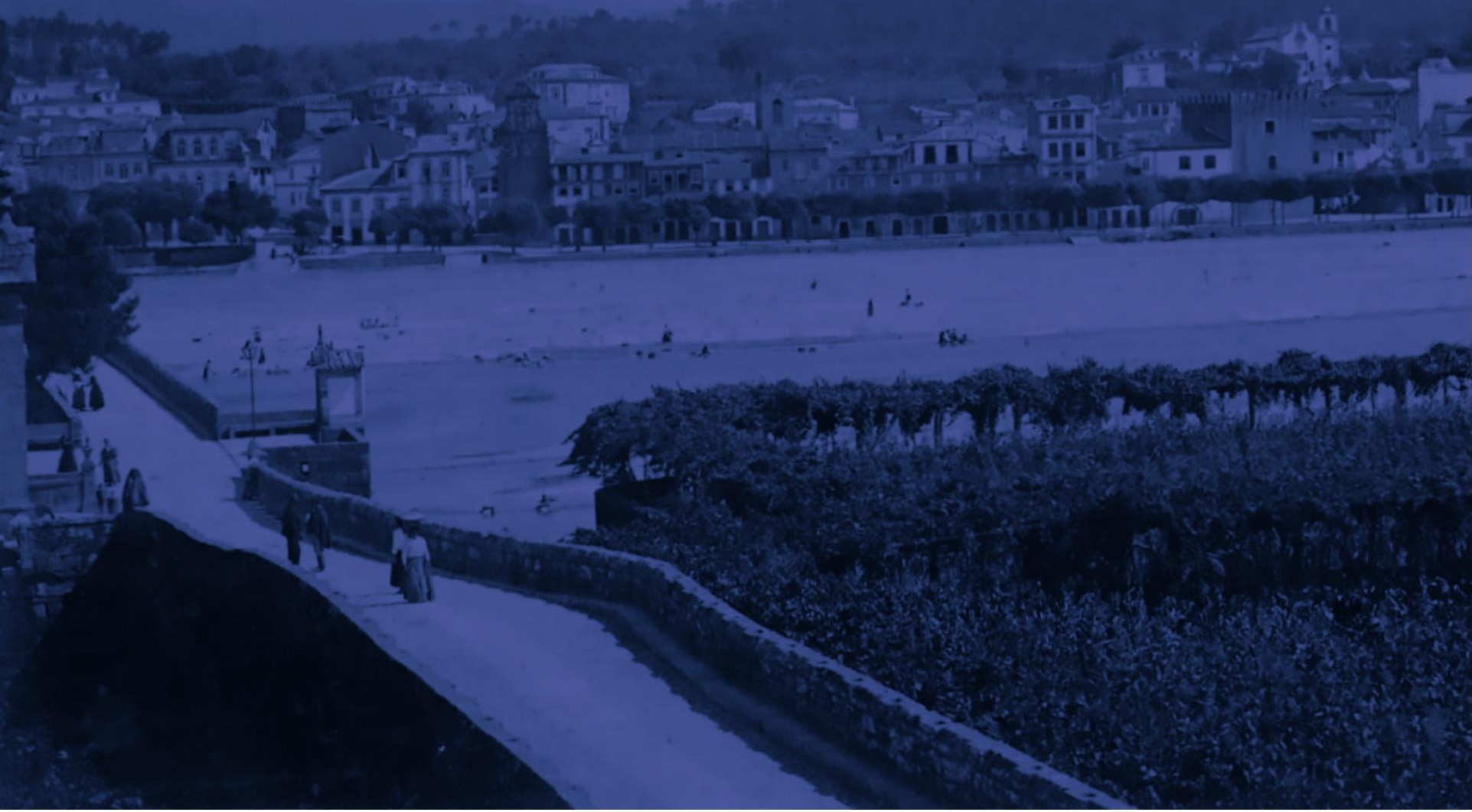




\section{A ATRIBULADA CRIAC̄̃̃O DA BIBLIOTECA PÚBLICA DE BRAGA E O SEU ARROJADO BIBLIOTECÁRIO LIMIANO}

THE TROUBLED CREATION OF THE PUBLIC LIBRARY OF BRAGA AND THE LIFE OF THE BOLD LIBRARIAN BORN IN PONTE DE LIMA

A criação da Biblioteca Pública de Braga, uma das primeiras da modernidade em Portugal, e uma breve sociobiografia de Manoel Rodrigues da Silva Abreu, seu primeiro bibliotecário, são apresentadas no contexto das relações socioeconómicas, culturais e de poder político das décadas iniciais da existência dessa Biblioteca. Alguns episódios da criação e da consolidação da Biblioteca, assim como da vida profissional do bibliotecário serão destacados proporcionar uma leitura aprofundada a partir de um caso singular. A análise e interpretação deste caso encerram capacidade para esclarecer não só a história das bibliotecas públicas em Portugal como para fornecer elementos enriquecedores de um quadro mais amplo, para este período da história cultural de Braga e do país.

The creation of the Public Library of Braga, one of the first of the modern times in Portugal, and a brief sociobiography of Manoel Rodrigues da Silva Abreu, the first librarian, are here presented within the context of the social, economic, cultural and political power relations of the initial decades of the Library's history. Some episodes of the creation and of the consolidation of the Library, as well as some episodes of the librarian's professional life will be outlined to facilitate a wider reading. While building from specificity, the analysis and interpretation of this case enclose an explanatory capacity addressed at a wider framework, in what concerns both the history of public libraries in Braga, and the understanding of the cultural history of this period in Braga and in Portugal.
BBBLIOTECAS PÍBLICAS, BRAGA, MANOEL RODRIGUES DA SILVA ABREU,

ESTUDOS DE BIBLIOTECAS, SOCIOBIOGRAFIAS, ESTADO MODERNO

PUBLICLIBRARIES, PORTUGAL, LIBRARY STUDIES, SOCIOBIOGRAPHIES, THE MODERNSTATE 


\section{PAULA SEQUEIROS ${ }^{[1]}$}

\section{Introdução}

A biblioteca pública moderna é objeto, em Portugal e a partir dos finais do séc. 19, de ação política e de legislação orientadas para complementar o sistema educativo, instituído em simultâneo pelo novo poder da burguesia durante a revolução liberal.

Para entender o alcance e inserção desta movimentação e das medidas legislativas na sociedade de então, é necessário começar por evocar várias outras dimensões sociais, culturais e políticas que teceram a trama contextual onde essa medida se entreteceu. A estruturação dessa trama foi o processo de industrialização e comércio base colonial, o qual dava forma e assentava nas maiores aglomerações urbanas e nos inovados meios de transporte e comunicação. Sistemas nacionais de ensino são desenhados para responder aos requisitos da produção, das trocas internacionais, do funcionalismo do Estado e da construção das identidades nacionais na sua relação com as línguas.

Esse século foi marcado, do lado dos poderes institucionais, pela proclamação e consolidação dos vários estados e por novos mapas políticos onde se marcaram não só as fronteiras europeias dos centros do poder como as dos territórios coloniais ou ex-coloniais. A construção das identidades nacionais ganhou relevo nas políticas e na cultura, enquanto eram redefinidos os conceitos-base para a atribuição de papéis de género, de classe e de raça. As bibliotecas públicas criadas nesse século em vários países da Europa, foram um instrumento da penetração das línguas nacionais, dominantes ou oficiais. A imprensa periódica e a produção do romance ganham neste período destaque e centralidade na área cultural, facilitados pelo extensão da literacia e do leitorado.

O caso da criação e da consolidação da Biblioteca Pública de Braga, uma das primeiras do país a ser instituída por lei, em 1841 (Carta de Lei, 13 de Julho), revela-se, após uma análise crítica situada no tempo e no espaço, como um processo atribulado, de conflito intenso e continuado, com capacidade para esclarecer não só a história das bibliotecas públicas em Portugal como para fornecer elementos enriquecedores de um quadro interpretativo mais amplo, cultural e geograficamente. Este caso encerra uma capacidade explicativa particular quanto aos seguintes aspetos: as relações de poder em torno da propriedade pública; as relações entre as diferentes classes sociais; as relações entre o aparelho de Estado liberal central, uma Câmara e a Igreja Católica em Braga; a formação dos intelectuais que moldaram as formas e as práticas daquelas novas instituições bibliotecárias.

Começarei por chamar a atenção para uma primeira particularidade deste caso: a longa espera en-

\section{A biblioteca pública moderna} é objeto, em Portugal e a partir dos finais do séc. 19, de ação política e de legislação orientadas para complementar o sistema educativo, instituído em simultâneo pelo novo poder da burguesia durante a revolução liberal.
[1] INVESTIGADORA

DOCENTRODE ESTUDOS SOCIAISDA UNIVERSIDADE DE COIMBRA. 
tre a assinatura da Carta de Lei institucionalizadora, em 1841, e a efetiva plena abertura ao público, a qual só teve lugar na realidade, não com a inauguração oficial de 1857 , mas com a segunda abertura já em 1862. Responder a esta questão é um dos objetivos deste trabalho para o que convocarei ações e visões e de grupos sociais e instituições diversas quanto ao que entendiam ser a finalidade e a necessidade de uma Bibliotheca Publica. Note-se que usarei a a ortografia atualizada nos textos citados, exceto nas referências bibliográficas e nos nomes próprios pelas razões habituais de normalização e racionalização da bibliografia. Retenho a grafia original do nome próprio do bibliotecário, Manoel, embora boa parte das memórias e histórias posteriores à sua morte o refiram como Manuel.

Outro aspeto que destacarei é o cruzamento da biografia do primeiro bibliotecário, Manoel Rodrigues da Silva Abreu (M.R.S.A.) (1793-1869) e da teoria biblioteconómica por este produzida. As filiações políticas e os episódios que viveu como refugiado políti$\mathrm{co}$, as suas práticas profissionais como tradutor, articulista em jornais e revisor literário, as ligações intelectuais, políticas e jornalísticas de M.R.S.A. - Almeida Garrett, François Guizot, Alexandre Herculano, António Feliciano de Castilho -, proporcionarão, espero, uma análise enriquecida do que poderia ser um bibliotecário, figura então incipiente e que Silva Abreu encarnou. $O$ contexto de conflito político-militar prolongado aparece como analiticamente esclarecedor e avivador dos contrastes e conflitos urdidos na trama cambiante das relações económicas, sociais, educativas, literárias: não é possível ignorar a constante influência do ideário e da ação política, da formação de diferentes grupos de interesse com caraterização social própria nos campos do ensino e da cultura, assim como a emergência de um novo funcionariado do Estado e sua articulação com os órgãos do poder político.

Por fim, realço que entender o conflito político-militar prolongado, marcado pelas invasões francesas e a entrada do exército britânico, pelas lutas liberais e pela afirmação do estado burguês, permite avivar os contrastes e assim esclarecer um período pontuado por mudanças tempestuosas. Relevarei por isso a influência de algum ideário sociopolítico, da formação de diferentes grupos de interesse nos campos do ensino e da cultura. Relevo será dado também ao facto de que Abreu utilizou habilmente a imprensa periódica, tendo feito parte de um novo funcionariado do Estado.

$\mathrm{O}$ ponto de partida para reconstruir a história da criação da Biblioteca Pública de Braga foram os escritos de Alberto Feio (1920). Note-se que Feio foi o bibliotecário nomeado pelo governo da República em 1911 para essa mesma biblioteca. Desde já adianto que essa narrativa inicial, quase uma novela romântica em torno do bi- bliotecário-herói fundador, evocará em quem o leia semelhanças entre traços daquele contexto e o atual, de um modo curioso.

Para compreender em profundidade o processo inicial desta $\mathrm{Bi}$ blioteca Pública, adicionei outras visões das ciências sociais sobre o período em questão. Procurei um olhar abrangente, menos centrado nos eventos e mais focado nos processos históricos, sociais e culturais. Evitei, no entanto, que se perdesse a vivacidade e a riqueza incluindo alguns detalhes que me cativaram particularmente durante a pesquisa e que poderiam agora ser emprestados para a uma leitura animada do que se segue.

\section{Bibliotecas modernas, primeiros bibliotecários}

Em Portugal, a biblioteca pública é instituída pelo poder liberal a partir dos finais do séc. 19, com a finalidade de ser um particular coadjuvante do sistema instrutivo. $\mathrm{Na}$ Europa, e dentro dos diferentes contextos regionais, a criação da biblioteca moderna foi uma realidade histórica e socialmente conformada pela normalização das línguas nacionais e pela introdução de sistemas nacionais de ensino, uma e outra ligadas à proclamação dos estados e redesenho das fronteiras e dos territórios colonizados ou ex-coloniais, à construção das identidades nacionais, ao redesenho e reatribuição de papéis de classe e de género. Um processo de crescente industrialização, de base 
As ligações intelectuais, politicas e jornalísticas de M.R.S.A., os episódios de refúgio político por que passou, proporcionarão uma análise enriquecida da Biblioteca e do seu bibliotecário. colonial, e a construção legal e institucional do aparelho de estado burguês completam o cenário fundamental requerido pela história e análise de caso que se segue. No campo cultural e educativo, destacam-se ainda uma forte atividade da imprensa periódica e a produção do romance, acompanhados pelo incremento da literacia e do público leitor.

O estudo do caso da conflituosa instituição na lei (1841) e a morosa consolidação da Biblioteca Pública de Braga (1862, abertura plena ao público), umas das primeiras criadas no país, encerra interessante capacidade explicativa sobre as relações de poder em torno da propriedade, do ensino e da formação intelectual, nomeadamente entre as diferentes classes sociais e entre o aparelho de Estado liberal, a Câmara de Braga e a Igreja Católica. Parte indissociável deste estudo é a análise da biografia e da teoria produzida pelo seu bibliotecário primeiro, Manoel Rodrigues da Silva Abreu (M.R.S.A., como por vezes assina) (1793-1869). Formado em Direito, é interessante acompanhar as suas afiliações políticas, as suas práticas como secretário pessoal de Garrett, como tradutor, escritor para jornais e revisor literário. Essa capacidade explicativa pode ainda estender-se à análise das visões $\mathrm{e}$ ações de grupos sociais diversos quanto à finalidade e necessidade de uma biblioteca pública, particularmente da pequena burguesia da cidade de Braga. A agência que esse bibliotecário encarnou, como intelectual público, figura então incipiente, a confrontação que sentiu como membro de uma nova profissão que reclamava um espaço social de reconhecimento e intervenção merece, entendo, uma contextualização cuidada. As ligações intelectuais, políticas e jornalísticas de M.R.S.A., os episódios de refúgio político por que passou, proporcionarão uma análise enriquecida da Biblioteca e do seu bibliotecário. Do exílio terá trazido também, imaginamos, a frequência de bibliotecas, Rennes possuía então várias bibliotecas, incluindo uma vasta municipal.

A abordagem que aqui utilizo dirige-se a superar a ideia de que a biblioteca moderna foi determinada por um ato legislativo e administrativo, fora das esferas onde as relações económicas e de poder político se desenhavam, e de que a instituição emergente se construiu como instituição e representação de paz e entendimento na sociedade. Ela foi, pelo contrário, claramente um produto da guerra, da legitimação de uma nova forma de propriedade capitalista, do conflito social, das circulação internacional de ideias, uma desejada aliada estratégica da nova ordem sociopolítica.

\section{O caso da criação e da consolidação da Biblioteca Pública de Braga}

[E]m área mui circunscrita, [a bibliotecal pode instruir e moralizar um milhão de entendimentos $e$ de vontades (carta 
de Silva Abreu a Garrett, cit. por Francisco Gomes de Amorim (1884).

A história inicial da Biblioteca Pública de Braga contém muitos dos ingredientes da novela romântica. A época convocada e a construção dos factos históricos, que pretendo aqui fazer, permitem cruzar factos e processos: uma nova instituição é criada, a biblioteca pública; surge e ganha relevo um tipo novo de intelectual, o intelectual público, que se envolve política e socialmente e que utiliza para tanto os meios de comunicação então emergentes, sobretudo os jornais; surge ainda, para a burocracia do Estado burguês, recente e em afirmação, um funcionariado que ensaia a sua própria relação com os poderes políticos central e local.

A longa série de conflitos político-militares da instauração da nova ordem liberal, fornece um contexto esclarecedor para o ocorrido então em Braga. É visível e assumida a influência do ideário e da ação política, das alianças de diferentes grupos de interesse, com caraterização social própria, nos campos do ensino e da cultura. Essa Biblioteca foi palco desses conflitos, até no domínio físico, mas sobretudo no simbólico, não fosse ela produto da revolução e alvo político para várias formas de conservadorismo, e não fosse também agente institucional de algumas das mudanças que então se viveram na região e no país.

A cidade do Porto obtivera na lei uma primeira biblioteca pública e a nomeação do primeiro bibliote- cário, em julho de 1833 (Rebelo, 2002; Cabral, 2009/2010), na sequência e como retribuição pelos serviços prestados pelos defensores do Cerco do Porto.

Meses antes, tinha sido publicada a lei que extinguira no Continente os conventos masculinos e os expropriou de bens fundiários, edifícios incluídos, mas também de livros, bens que integraram o património do Estado. Os fundos confiscados foram administrados pelo Depósito das Livrarias dos Extintos Conventos, regulamentado em 1834, antecipando a distribuição por bibliotecas públicas a criar, com destaque para as capitais de distrito, estipulada em Portaria do ano seguinte (Barata, 2005, p. 40). Estes livros, e depois os confiscados a miguelistas, teriam esse destino. Intenção e finalidade essas que serão legíveis em sucessivos diplomas legais publicados durante toda a década de 30 e até à de 50. Carlos Alberto Rebelo refere em detalhe este processo para as várias cidades do país (2002, sec. 4.3.1).

A criação da Biblioteca Pública de Braga é assim uma resposta à oportunidade levantada pelo governo central.

Interessante é considerar que as leis das bibliotecas deveriam estar já pensadas, senão esboçadas, bem antes durante o exílio dos liberais perseguidos. As personalidades que lideraram os processos determinantes da génese das bibliotecas públicas modernas - sistema nacional de ensino, expropriações, fomento da língua e literatura, leis da imprensa e censura, direitos autorais - todas se cruzaram, eventualmente e em primeiro lugar na universidade, mas logo nas lutas liberais, nos locais de exílio nos Açores, em França e em Inglaterra. Nestes países dedicaram-se à escrita, à investigação, ao uso de bibliotecas e arquivos, aos contactos com outros intelectuais e políticos. Vários estarão, depois, presentes entre as forças liberais resistentes ao cerco do Porto. A prioridade conferida à legislação de bibliotecas atesta como foram consideradas estratégicas para a constituição e consolidação da nova ordem política e cultural.

[...] e estabelecimento pois de bibliotecas públicas é o complemento de todo o sistema instrutivo, e não será sem fundamento dizer-se que pelo número destes estabelecimentos $e$, cada um dos países civilizados se pode avaliar sem erro, a instrução comparativa dos seus habitantes. (Cândido José Xavier, ministro e secretário de Estado dos Negócios do Reino, relatório anexo ao Decreto de 9 de julho de 1833, cit. por Rebelo, 2002, p. 86 e Barata, 2005, p. 41).

Desde 1840, e precedendo organicamente a criação da Biblioteca de Braga na lei, Abreu estava nomeado pela coroa como oficial para o distrito, tendo assumido a organização, catalogação e avaliação dos fundos confiscados na região. Começou a trabalhar recolhendo duas dezenas de livrarias - nome corrente para as bibliotecas - e ordenando, catalogando e avaliando os fundos que pretendeu destinar 
a Braga e a outras no distrito, nomeadamente Guimarães. É designado bibliotecário em Carta Régia de 26 de agosto de 1842 (Abreu, 1863). O bibliotecário será um protagonista destacado na defesa da biblioteca pública, como adiante exporei. Nascido em Ponte de Lima nos fins do séc. 18, manteve-se a trabalhar na biblioteca até ao final da sua longa vida.

Os registos de memórias feitos por seus contemporâneos foram tratados com fontes sujeitas a escrutínio crítico, tendo em conta aliás que a historiografia legitimada se inicia nesse mesmo momento e que tem vindo a ser reescrita.

Antecedendo a instituição biblioteca pública, formaram-se gabinetes de leitura (associações, clubes) desde o séc. 18 na Europa e que perdurarão, em alguns casos, pelo séc. 20 dentro. Enquanto organizações associativas, o acesso granjeava-se pela aprovação dos dirigentes e pagamento de uma quota, sendo espaços dirigidos especialmente ao entretenimento e convivialidade da classe média. Em Braga existiu um desses gabinetes, a Sociedade Democrática Recreativa (Rebelo, 2002, p. 77), ativa na edição de algumas brochuras na década de 1880 .

No caso das bibliotecas, privadas, de clérigos e aristocratas, e comparando com as bibliotecas públicas - além das diferenças patentes no regime de propriedade das coleções e até dos edifícios -, a entrada era concedida mediante privilégio, consubstanciado por vezes em cartas de resposta aos requerentes. $\mathrm{Na}$ realidade, e em geral, tratavam-se de estudiosos com acesso à rede de influência dos proprietários das coleções que aceitavam permitir e tutelar as suas leituras.

Já a entrada na biblioteca pública não dependeria de um privilégio. Requerendo formalmente apenas a condição de cidadão, proclamava-se a oportunidade de aprender acedendo aos livros. Começava a formar-se no continente europeu, a partir de meados do séc. 19 e início do 20, a representação social de que a biblioteca pública é para todos o que querem aprender, conforme será veiculado no discurso dos seus promotores. Tomando como referência Portugal, foi necessário superar adversidades várias, lidar com um grande lapso de tempo para consolidar a biblioteca como instituição representada pelo poder político como de utilidade para a sociedade. É isso mesmo, atestam o longo processo de abertura das bibliotecas, processo contestado e argumentado a partir de diferentes posicionamentos na sociedade, e que ficou impresso, nomeadamente, pelas posições de classe e de género dos agentes sociais envolvidos. Para que fosse instalada a $\mathrm{Bi}$ blioteca de Braga, é atribuído o edifício do convento dos Congregados, ou dos Neris, depois de expropriado pela administração, ocupação que se verá várias vezes ameaçada. Aí Abreu terá de se bater, até no sentido físico da palavra. Fá-lo-á contra a entrada na biblioteca de soldados ora franceses ora ingleses, em diversos momentos dos conflitos militares na cidade. Fá-lo-á ainda para impedir a destruição dos livros mais preciosos por incúria e por roubo individual ou saque de guerra. Terá também de acautelar contra incêndios e infiltrações de água num edifício muito degradado e cujo uso efetivo é disputado por outras utilizações que podem colocar os fundos em risco. Terá de se opor constantemente a ataques à instituição recém formada, e a si mesmo, membro de uma profissão com débil reconhecimento social, por parte representantes de diversas forças políticas locais e centrais. As verbas eram disputadas acesamente nos órgãos camarários para outros destinos, sobretudo para obras: um setor da burguesia bracarense ansiava por um passeio público onde se exibir de acordo com o seu estatuto de classe, análogo aos de grandes cidades europeias; um outro grupo exigia mais um fontanário; a biblioteca e os seu livros, não eram uma prioridade. Foi preciso levar a questão até às Cortes para fazer prosseguir a ideia. Vejamos de seguida alguns episódios desta contenda encarniçada.

O Conselho de Instrução Pública propõe em 1843, na Câmara de Deputados, que a recuperação do edifício seja custeada parcialmente pelo município. Mas o seu novo presidente suspende as obras aprovadas. Ataca o bibliotecário pessoal, profissional e politicamente, acusa-o de má conduta familiar (não coabitava com a mulher e os 
filhos) e religiosa (não era visto na missa), de ociosidade e alega que Silva Abreu "suspira por uma câmara de agitadores" (Feio, 1920, p. 22-24). Suspende-lhe o salário e despede o ajudante.

À Câmara dos Deputados nacional é reenviada, em 1844, uma proposta de lei para financiamento dos pagamentos ao bibliotecário, à compra de livros e material para a biblioteca. Anteriormente aprovada, a sua regulamentação fora bloqueada por uma delegação da cidade que conseguiu, em maio, persuadir os deputados da ausência de verbas locais. Abreu qualificara a delegação como "um anacronismo neste século", composta por "7 homens que não entendem a sua missão", "oposta aos desejos duma cidade eminentemente científica e fabril; é enfim uma vergonha" para "toda a cidade e o município". Dias mais tarde, em junho, será Almeida Garrett que, na Câmara dos Deputados, frisará a importância duma biblioteca naquela cidade e, ridiculariza os vereadores que pretendiam um chafariz "na terra dos chafarizes", depois de terem obtido uma biblioteca "cuja casa the foi dada, cujos livros não foram comprados à sua custa", recusando-se depois a sustentá-la e a "concorrer para a manutenção do bibliotecário" (Feio 1920:18-19). Garrett faz publicar as contas da Câmara em periódico local como prova da suficiência para os gastos pretendidos.

Com o salário suspenso, e alegando falta de meios próprios, Abreu começara a vender bens pessoais incluindo os seus "queridos livros". Indigna-se por sentir que a situação deveria provocar "escândalo de todos os homens de bem, que sabem apreciar como cumpre a vida do pobre honesto, no meio de tanta gangrena, imoralidade e prostituição de alguma gente rica" (Feio 1920:25).

A resposta do presidente camarário é afixada em pasquim ${ }^{[2]}$ nas ruas, desafiando sarcasticamente a população a coletar-se, já que há quem afirme tanto desejar a biblioteca.

No início de 1844, o deputado Lopes Alheira defende empolgadamente o financiamento da biblioteca:

Eu ouvi dizer, Sr. Presidente, que um bomem dos subúrbios de Braga, hoje presidente da Câmara daquela Cidade, homem que, não obstante ser Bacharel em Direito, já não quer saber nem de mais livros, nem de mais letras, que as letras de câmbio (e alguém lhe acha razão...) viera, de propósito, de Braga à Capital para queimar a Biblioteca juntamente com o Bibliotecário!... E não direi eu, Sr. Presidente, se o homem obrou por instinto, se por efeito de um plano combinado: mas posso afirmar, que a existência de uma Biblioteca em Braga é, pelo menos, um insulto, um epigrama terrivel, lançado contra uma Câmara Municipal, que faz timbre de ser ignorante... (cit. por Feio, 1920, p. 26)

Demonstra, a seguir, que não há falta de dinheiro, como atestam as propostas de apoio local aos Passeios Públicos "tão ridículos quan-
As verbas eram disputadas

acesamente nos órgãos camarários para outros destinos, sobretudo para obras: um setor da burguesia bracarense ansiava por um passeio público onde se exibir de acordo com o seu estatuto de classe, análogo aos de grandes cidades europeias; um outro grupo exigia mais um fontanário; a biblioteca e os seu livros, não eram uma prioridade. 
to desnecessários” ou à construção de um Teatro (Feio, 1920, p. 27). No final do ano de 1844, o novo governador civil em Braga intervirá para a reversão dessas decisões. A ocupação dos Congregados, como referi, rodeou-se de peripécias e momentos dramáticos. No edifício os fundos terão uma conflituosa convivência com outros ocupantes forçando a constantes deslocações dos livros para outras salas (Feio, 1920). Foi o caso da instalação aí do Liceu Nacional, a partir de 1841 e da criação ainda de um internato em 1851. Mais tarde alojar-se-ia o Quartel General da Divisão do Minho. A Cerca dos Congregados, em 1844, passou a servir como lugar para teatro e feira. Estes usos ameaçavam, entendia Silva Abreu, a segurança física dos livros, situação agravada com a Maria da Fonte e a Patuleia, com enfrentamentos militares entre cartistas, setembristas e miguelistas, movimentações populares e assaltos a quartéis. Noutras localidades houve casos de frequentes roubos e extravios no quadro do confisco e do depósito provisório, com livros fechados por tempo excessivo, por colocar em bibliotecas, quadro agravado por mudanças de instalações e conflitos político-religiosos (Barata, 2004). O bibliotecário conheceria certamente esses casos e sofreu a situação no seu caso. Queixou-se Abreu de ter de fazer reparações (do seu bolso) para salvar os livros encerrados, para poderem ser os "vinte e tantos mil expostos [sic] salvos de insultos" (Feio, 1920, p.
36-37). As obras esperadas desde 1842 só se farão, em pequena parte, em 1853. Note-se que Alexandre Herculano faz uma inspeção à Biblioteca em 1854 e ele mesmo desaprova a partilha do conjunto edificado por outras entidades. $\mathrm{O}$ salão, mistamente de leitura e de depósito, será remodelado dois anos mais tarde. Em 1857 recebeu um mezanino decorado a branco e ouro, mas sem a rede anti-furto habitual para casos de acesso público. Em 1856 o Liceu desocuparia o edifício na sequência de irregularidades praticadas no internato. Mas, sabendo Abreu que outra direção pretendia reabri-lo, mandou imprimir um "Recurso" com a denúncia pública e apelou a todos os quatro jornais de Braga para que visitassem a Biblioteca e testemunhassem as suas condições. O Murmúrio, O Moderado, a Atalaia Catholica e o Bracarense apoiam-no, seguidos por jornais de Valença e Lisboa, como o Instrucção Publica que transcreve aquele documento.

Nesta linha, de depois de tanto obstaculizar a abertura ao público, a Câmara decide fazer a inauguração oficial em 16 de setembro de 1857, para coincidir com a visita de Pedro V a cidade, em comemoração do seu aniversário. Decisão contra a vontade do bibliotecário que entendia não haver tempo de suficiente - menos de um mês - , entre a conclusão das obras em curso no salão e essa data. Agora com estantes divididas à altura pelo referido mezanino, a transferência para o salão dos livros até

\section{(...) a Câmara decide fazer a} inauguração oficial em 16 de setembro de 1857 , para coincidir com a visita de Pedro $\mathrm{V} a$ cidade, em comemoração do seu aniversário. Decisão contra a vontade do bibliotecário que entendia não haver tempo de suficiente - menos de um mês - , entre a conclusão das obras em curso no salão e essa data. 


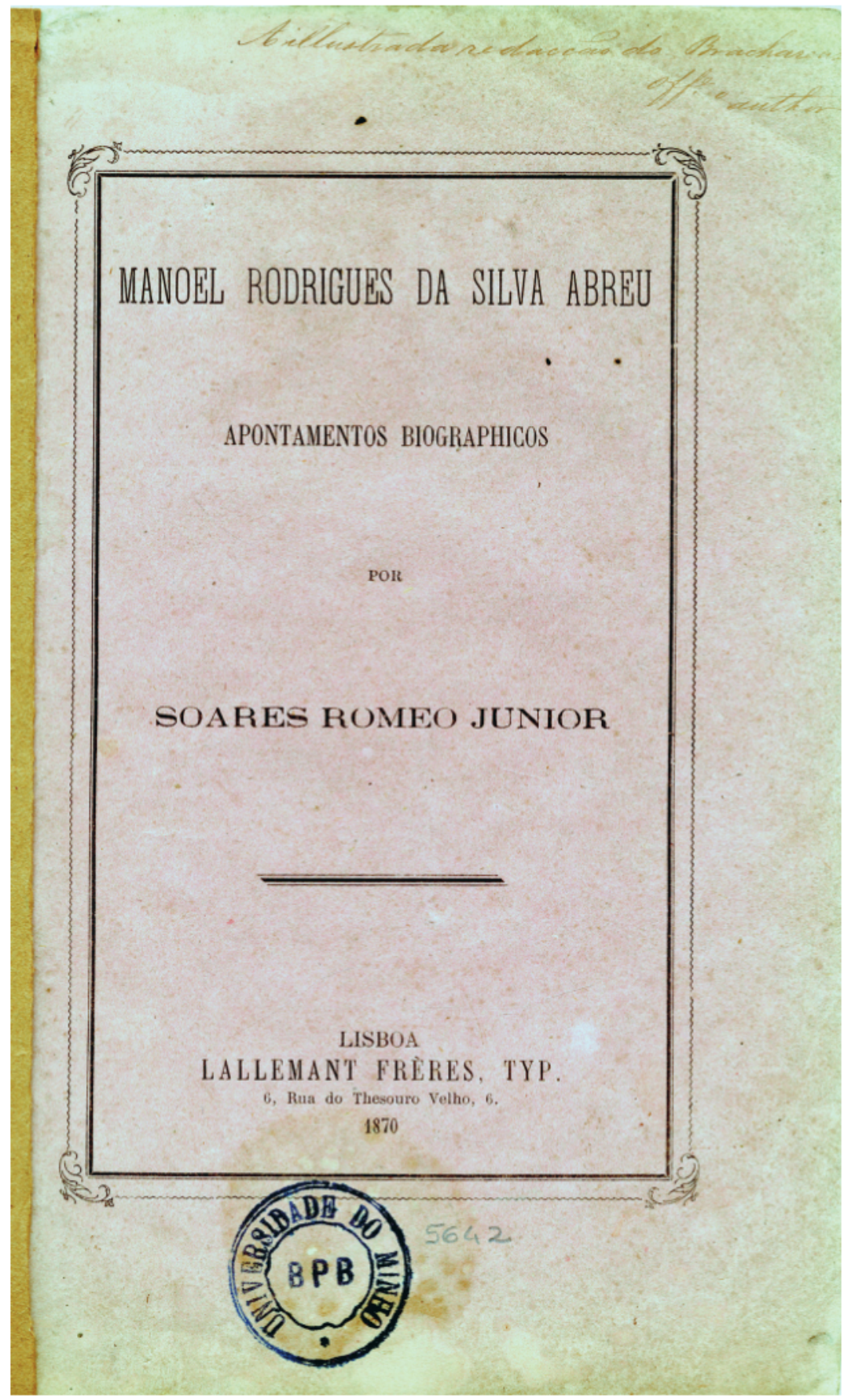

FIGURA 2.

Capa "Manoel Rodrigues da Silva Abreu -

Apontamentos Biographicos” por Romeu Junior 
aí ordenados por matérias nas antigas celas conventuais, exigia uma reorganização espacial que o levara, aliás, a idear um novo sistema de colocação de implementaçãoc omplexa. Abreu recusa odedecer. Produziu-se a desorganização nas coleções com colocação, sem os seus critérios biblioteconómicos, entregue a carpinteiros. Somado a isto, na cerimónia de inauguração, o rei entalou uma perna no soalho carcomido que se rompeu à sua passagem. Depois desta "patranha de aberturas ficticias", palavras de M.R.S.A, e tal como o fizera após a vitória setembrista e em oposição à ascenção de algumas figuras locais ao poder, o bibliotecário demite-se. A biblioteca teria de fechar poucos dias depois, só reabrindo as portas ao público em 1862. Pertencer aos "homens de luzes" na oposição, condição em que Abreu se auto-incluía, trazia consequências amargas para si e pela terceira de viu afastado do trabalho, sem salário.

Em defesa do seu papel invocou mais de uma vez o seu estatuto como oficial do distrito, bibliotecário de nomeação régia, não se sentindo compelido por isso a obedecer à Câmara. Em defesa do seu estatuto profissional, invoca que não tem profissão "mecânica”, isto é, não é trabalhador manual a quem compita carregar livros ou fazer tarefas que considera "indecentes", afirmando-se como um dos raros letrados que exerce a profissão, a qual demonstra que requer "ciência". Invoca ainda ser garante da missão de que foi incumbido pelo estado, "depositário único de preciosíssima fazenda nacional, e conservador responsável dela“, acusando a Câmara de querer ser "senhora absoluta" das bibliotecas do distrito, "como qualquer particular dispõe da sua fazenda própria" (Abreu, 1857, p. 4).

Nova inspeção do Conselho de Instrução Pública à Biblioteca corrobora as reclamações de Abreu (Ribeiro, 1914) e recomenda ao rei reforço do pessoal e concretização dos investimentos adiados. Refere ainda o relator, informação assinalável:

Desta época [janeiro] a 11 de Setembro frequentaram a Biblioteca 2072 leitores. [...]

O grande numero de alunos seculares $e$ eclesiásticos, que aí cursam as aulas; a numerosa cleresia, que concorre à capital da província eclesiástica; e sobretudo a importância desta bela cidade, no centro de uma província tão rica, populosa e industrial, por certo que pediam uma biblioteca melhor ordenada, e mais completamente servida de pessoal indispensável.

À Câmara Municipal pertence suprir estas faltas, curando dos reparos e obras indispensáveis, que o Bibliotecário particulariza, como deve e é obrigado por lei, propondo também, em conformidade com a lei, a nomeação de um segundo Bibliotecário, e destinando para o serviço da Biblioteca os guardas ou serventes sem os quais não pôde haver ordem e segurança no seu serviço. E V. M. atendendo às graves considerações expostas, não deixará de fazer cessar a indesculpável negligencia da mesma Câmara. (Ribeiro, 1914, p. 80).

\section{Vida de M.R.S.A.}

Imaginemos a pessoa a partir de descrições que nos chegaram dele. A sua atuação na Biblioteca Pública de Braga constituirá, provavelmente, informação mais substanciosa. Manoel, filho de Francisco António e de Jatrudes, moradores na rua de São João de Fora, vila de Ponte de Lima, nasceu a 14 de agosto de 1793 nessa vila (Arquivo Distrital Viana do Castelo, 1993). Cursou Direito em Coimbra e graduou-se em 1825 (Romeo Junior, 1870). Aí aderiu à maçonaria, tendo sido secretário da Sociedade dos Jardineiros, na continuidade provável da anterior sociedade secreta Keporática, que Garrett e Passos Manuel integraram (Santos,1979).

Face ao avanço das forças miguelistas, em 26 maio de 1828 foge de Ponte de Lima - sem se despedir da mulher e filhos - e refugia-se no Porto. Embarca para Londres e algum tempo depois parte para Rennes onde permanece até 1832. Num texto fortemente encomiástico, Romeo Júnior (1870) biografa e faz o elogio póstumo de Manoel Rodrigues da Silva Abreu. A abrir, os líderes liberais são pintados com as cores nacionalistas devidas aos continuadores da grandeza imperial passada, que o autor invoca, colocando M.R.S.A. nessa descendência. Refere-se-lhe como tendo sempre sido tolerante ideologicamente, tranquilo na exposição das suas ideias, com uma verticalidade de caráter - que o levaria a dissociar-se de alguns 


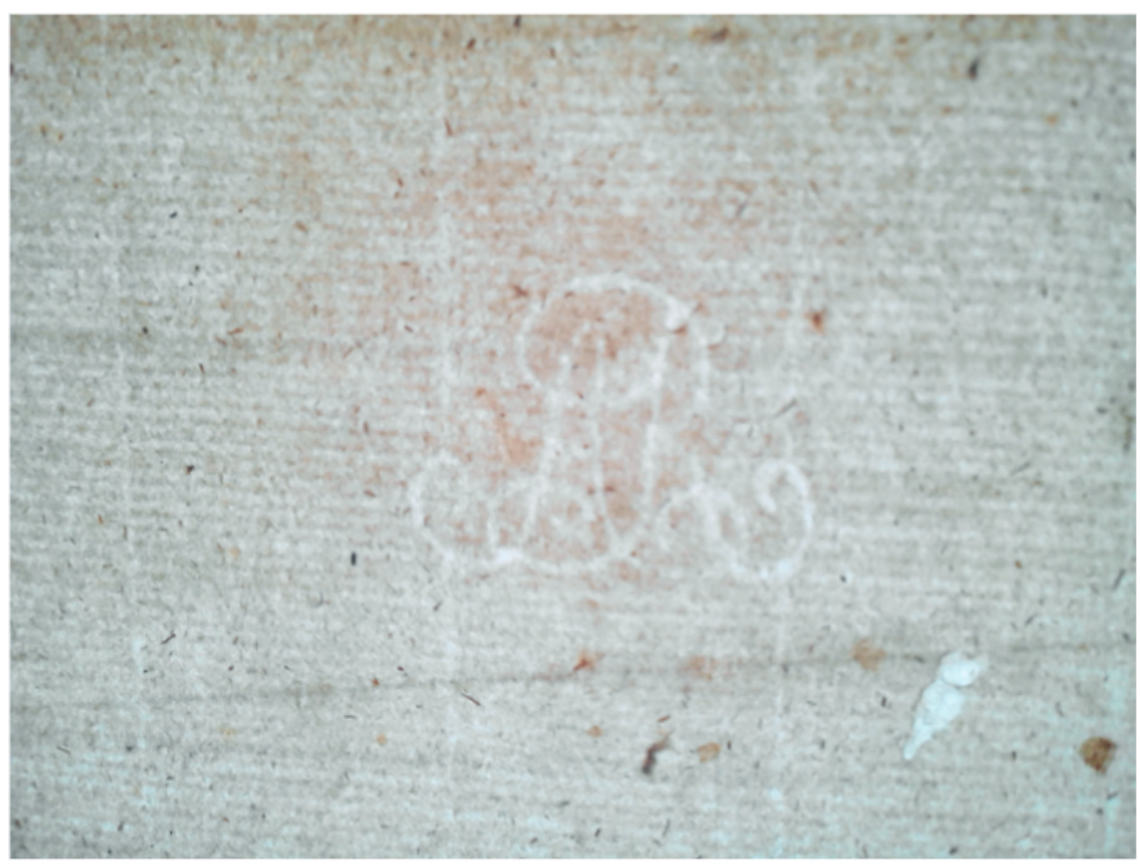

FIGURA 3.

Marca d'água

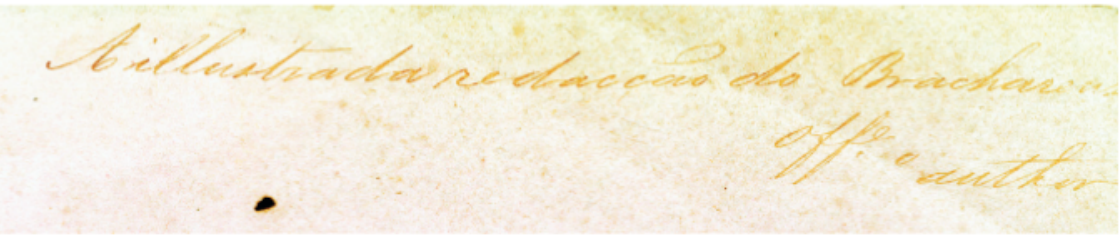

FIGURA 4.

Dedicatória companheiros de luta por questões de princípio -, avesso a se servir do lugar para proveito próprio.

[Aos] 72 anos, era alto de estatura, rosto claro e comprido, nariz proeminente, olhos escuros e a fronte espaçosa, coroada de alvíssimas cãs. Apesar dos anos, conservou sempre juvenil o seu espírito, e a sua conversação foi sempre atraente; e quem pela primeira vez o escutasse, conhecia facilmente que tinha ante si um homem respeitável. (Romeo Junior, 1870, p. 15).

Diz dele Manuel Pinheiro Chagas (1885): era "modesto, de uma timidez quase selvagem, cheio de honrados e invencíveis escrúpulos". Considera-o "em literatura um retardatário", com ideias muito clássicas, encerrado no ideário de 1820, "copiando Filinto Elísio que adorava” e com um diminuto acolhimento ao romantismo.

Pouco depois da sua morte, o Diccionario Popular de Pinheiro Chagas, regista: "raro será o mancebo estudioso de Braga que não fale com entusiasmo" de Abreu que, apesar de deixar "poucos rastos de si na literatura portuguesa", conviveu "com os vultos mais eminentes da nossa revolução literária, tendo-se associado aos seus trabalhos e compartilhado os seus entusiasmos" (cit. por Martins, 2006, p. 44-45).

Refere-se ainda à sua ação profissional José Silvestre Ribeiro, no âmbito dos Apontamentos históricos sobre bibliotecas portuguesas (1914).

Abreu era um admirador de Herculano e ideologicamente seu pró- 
ximo. Produziu trabalho literário diverso, tal como uma versão de Eliézer traduzida a partir de Florian e versificada para português. No prólogo, enaltece o amor fraternal entre os cidadãos, sem o que nem teorias doutorais nem "tentativas de constituições e cartas", repetidas e "tão atraiçoadamente malogradas" dariam algum proveito (Abreu, 1839).

As suas capacidades literárias exerceram-se em peças jornalísticas que contraditavam as publicações da própria Câmara e dos interesses que se opunham à abertura de uma biblioteca, cujo controle lhes escapava.

Fez várias traduções, algumas por publicar, como refere Inocêncio no seu dicionário (Silva e Aranha, 1893, p. 303). Foi tradutor e revisor de traduções de autores como Garrett, Castilho ou Herculano. Durante o exílio de Garrett, com quem aparentemente coabitou, foi seu secretário pessoal (Silva, 1862). Escreveu "um folheto àcerca de biblioteconomia" onde propõe um método para racionalizar a colocação dos livros em estantes, a sua catalogação, a elaboração de "indicadores” por matérias e autores, tudo com um duplo objetivo: poupar tempo na ordenação dos fundos, na localização e recolocação nas estantes, e fornecer aos leitores a possibilidade de compulsarem esses índices - em encadernações de verbetes amovíveis por si desenhadas enquanto se deslocam na pesquisa pela estantaria (Abreu, 1857). Pela sua especialidade, esta será matéria para publicação posterior.

\section{A biblioteca moderna em questão}

A biblioteca pública moderna, emergente em Portugal, assente num período revolucionário que levou à consolidação do regime burguês, enfrentou vários constrangimentos pelo que ela própria, como nova instituição, requeria e questionava, tanto no tocante à propriedade, como às tutelas oficiais ou às finalidades da leitura pública, orientadas para um determinado leitorado.

A maneira como diferentes grupos sociais e políticos se posicionaram frente aos conflitos surgidos é esclarecedora das pretensões desses grupos naquela sociedade em mutação. A sua expressão foi partilhada e protagonizada por diversos intelectuais e políticos e tinha como desígnio central a formação de uma elite ilustrada. Como tal essa instituição moderna foi veículo da exaltação e do reconhecimento público dado aos novos intelectuais, de disseminação das ideias e das práticas liberais, mostrando uma dimensão simbólica requerida para uma identidade nacional que estava a ser construída.

A resolução, labor e persistência e ainda a inventividade gerada em momento de crise e conflito, foram características de Manoel. A memória do seu papel, esquecido no tempo, tem recentemente sido recuperado e continua, em meu entender, a merecer atenção.
Projeto ref ${ }^{a}$ SFRH/BPS/82215/2011, cofinanciado por Compete 2020, Portugal 2020 União Europeia-FEDER, e Fundação para a Ciência e Tecnologia.

A resolução, labor e persistência e ainda a inventividade gerada em momento de crise e conflito, foram características de Manoel. A memória do seu papel, esquecido no tempo, tem recentemente sido recuperado e continua, em meu entender, a merecer atenção. 


\section{BIBLIOGRAFIA}

- ABREU, Manoel Rodrigues da Silva - Bibliotheca de Braga: Manifesto. Braga, Typ. Luzitana, 1857.

- ABREU, Manoel Rodrigues da Silva Eliézer, ou a ternura fraternal: poema. Braga: Typ. na Rua dos Pelames, 1839.

- ABREU, Manoel Rodrigues da Silva. (1863). Novidades bibliotheconomicas, ou refutação de cinco absurdos, que geralmente, e há séculos, se soffrem no serviço das bibliothecas publicas, reduzidos todos eles à obediencia do simples senso comum. Braga: Typ. do Seminário dos Orphãos. Disponível em https://books. google.pt/books?id=EcJgAAAAcAAJ\&printsec $=$ frontcover $\& \mathrm{hl}=\mathrm{pt}-\mathrm{PT} \&$ source $=\mathrm{gbs} \_\mathrm{ge}$ summary_r\&cad $=0 \# \mathrm{v}=$ onepage $\& \mathrm{q} \& \mathrm{f}=$ false

- AMORIM, Francisco Gomes de - Garrett: memórias biographicas. Lisboa: Imprensa Nacional, 1884. vol. II. Disponível em http://purl.pt/6841.

\section{- ARQUIVO DISTRITAL DE VIANA DO} CASTELO - Registo paroquial de baptismo, 14 de agosto de 1793. PT-ADVCT-PRQ-PPTL35-001-00009_m0788.tif. Dísponível em: http://advct.dglab.gov.pt/.

- BARATA, Paulo J. S - Roubos, extravios e descaminhos nas livrarias conventuais portuguesas após a extinção das ordens religiosas: um quadro impressivo. Lusitania Sacra. $2^{a}$ série 16 (2004) 319-43.

- BARATA, Paulo J. S. - As bibliotecas no liberalismo: definição de uma política cultural de regime. Análise Social. XL:174 (2005) 37-63. http://analisesocial. ics.ul.pt/documentos/1218708931C8fGE6bl6Aw810U1.pdf.
- CABRAL, Luís - Alexandre Herculano: crónica breve de um bibliotecário. Cadernos BAD. 1/2 (2009/2010) 6-15. Disponível em <https://www.bad.pt/publicacoes/ index.php/cadernos/article/view/749>.

- CHAGAS, Manuel Pinheiro - Garrett e o seu tempo XIII. A Ilustração Portuguesa. $1^{\circ}$ ano: 40 (30 de março de 1885) 3-6.

- DOMingos, Manuela D. - Estudos de sociologia da cultura: livros e leitores do século XIX. Lisboa: Inst. Port. de Ensino à Distância, Centro de Estudos de História e Cultura Portuguesa, 1985.

- FEIO, Alberto - A Biblioteca Pública de Braga, notas históricas. Boletim da Biblioteca Pública e do Arquivo Distrital de Braga. I (1920) 5-76.

- LEMOS, Miguel Roque dos Reys - Anais Municipais de Ponte de Lima. $2^{\text {a }}$ ed. Ponte de Lima: Câmara Municipal de Ponte de Lima, 1977 [1936].

- REBELO, Carlos Alberto - A difusão da leitura pública: as bibliotecas populares (1870-1910). Porto: Campo das Letras, 2002.

- RIBEIRO, José Silvestre - Apontamentos históricos sobre bibliotecas portuguesas. Vol. XIX. Separata do Vol. I, da $1^{a}$ Série do "Boletim Bibliografico" (Coimbra: Imprensa da Universidade, 1914). <http://purl. pt/173/3/sc-66010-v/sc-66010-v_item3/index.html\#/0>

- ROMEO JÚNIOR, Soares - Manoel Rodrigues da Silva Abreu: apontamentos biographicos. Lisboa: Lallemant Frères, 1870.
- SANTOS, Maria de Lourdes Lima dos Sobre os intelectuais portugueses no século XIX (do Vintismo à Regeneração). Análise Social. 15:57 (1979) 69-115.

- SANTOS, Maria de Lourdes Lima dos. A elite intelectual e a difusão do livro nos meados do século xix. Análise Social. XXVI:2-3 (1992) 539-546.

- SILVA, Innocencio Francisco; Aranha, Brito. Manuel Rodrigues da Silva Abreu. In Diccionario bibliograhico portuguez. Lisboa: Imprensa Nacional, 1893. Vol. 16, p. 303.

- CARTA DE LEI 13 de julho - Diário do Governo. $2^{\circ}$ semestre 168 (18 de julho de 1841) 23. 